\title{
Liver Cirrhosis/Severe Fibrosis Is a Risk Factor for Anastomotic Leakage after Colorectal Surgery
}

\author{
Samuel Andreas Käser, ${ }^{1,2}$ Irina Hofmann, ${ }^{1}$ Niels Willi, ${ }^{3}$ \\ Felix Stickel, ${ }^{4}$ and Christoph Andreas Maurer ${ }^{1,5}$ \\ ${ }^{1}$ Department of General, Visceral, Vascular, and Thoracic Surgery, Hospital of Baselland, Rheinstrasse 26, \\ 4410 Liestal, Switzerland \\ ${ }^{2}$ Department of Visceral and Transplant Surgery, University Hospital Zurich, Rämistrasse 100, 8091 Zurich, Switzerland \\ ${ }^{3}$ Institute of Pathology, Mühlemattstrasse 11, 4410 Liestal, Switzerland \\ ${ }^{4}$ Department of Gastroenterology, Hirslanden-Clinic Beau-Site, Schänzlihalde 1, 3000 Bern-25, 3013 Bern, Switzerland \\ ${ }^{5}$ Department of Surgery, Hirslanden-Clinic Beau-Site, Schänzlihalde 1, 3000 Bern-25, 3013 Bern, Switzerland
}

Correspondence should be addressed to Christoph Andreas Maurer; christoph.maurer@hin.ch

Received 7 September 2016; Revised 27 November 2016; Accepted 8 December 2016

Academic Editor: Martin Hubner

Copyright (C) 2016 Samuel Andreas Käser et al. This is an open access article distributed under the Creative Commons Attribution License, which permits unrestricted use, distribution, and reproduction in any medium, provided the original work is properly cited.

\begin{abstract}
Purpose. Liver cirrhosis associated with high perioperative morbidity/mortality. This retrospective study determines whether liver cirrhosis represents a risk factor for anastomotic leakage after colonic anastomosis or not. Methods. Based on a prospective database with all consecutive colorectal resections performed at the authors' institution from 07/2002 to 07/2012 $(n=2104)$ all colonic and rectal anastomoses were identified $(n=1875)$. A temporary loop ileostomy was constructed in 257 cases $(13.7 \%)$ either due to Mannheimer Peritonitis-Index $>29$ or rectal anastomosis below $6 \mathrm{~cm}$ from the anal verge. More than one-third of the patients ( $n=691)$ had postoperative contrast enema, either at the occasion of another study or prior to closure of ileostomy. The presence of liver cirrhosis and the development of anastomotic leakage were assessed by chart review. Results. The overall anastomotic leakage rate was $2.7 \%$ (50/1875). In patients with cirrhosis/severe fibrosis, the anastomotic leakage rate was $12.5 \%(3 / 24)$, while it was only $2.5 \%(47 / 1851)$ in those without $(p=0.024)$. The difference remained statistically significant after correction for confounding factors by multivariate analysis. Conclusion. Patients with liver cirrhosis/severe fibrosis have an increased risk of leakage after colonic anastomosis.
\end{abstract}

\section{Introduction}

How to deal with patients with known or unexpected liver cirrhosis remains a major challenge in colorectal surgery as liver cirrhosis bears a high risk of postoperative complications [1-5]. Although the morbidity and mortality in these patients have been studied [6-10], surprisingly little is known regarding the relation between liver cirrhosis and anastomotic leakage as the most feared complication after colorectal surgery.

Although the healing of an intestinal anastomosis has often been studied but remains poorly understood [11], there are several disturbances that might influence the anastomotic healing in patients with liver cirrhosis: first, portal hypertension with impaired regulation of splanchnic blood flow [12], second, the protein metabolism disorder [13], and, third, the immune dysfunction syndrome especially in presence of ascites [14]. Indeed factors correlated with adverse surgical outcome in patients with liver cirrhosis are higher intraoperative blood loss reflecting portal hypertension, hypalbuminemia reflecting protein metabolism disorder, and the presence of ascites [15]. Furthermore the severity of liver disease correlates with postoperative morbidity and mortality [16].

To our knowledge only animal models have shown a relationship between liver cirrhosis and anastomotic leakage so far [17]. This study determines, for the first time, whether liver cirrhosis is a risk factor for anastomotic leakage after colorectal surgery or not. 


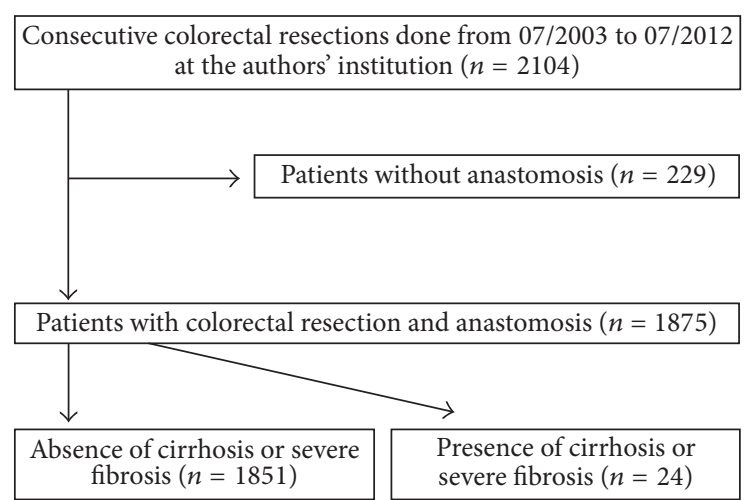

FIGURE 1: Flow diagram of the study methodology.

\section{Methods}

Based on an existing prospective colorectal database with all consecutive colorectal operations resections, all colonic and rectal anastomoses performed at the authors' institution from $07 / 2002$ to $07 / 2012$ were retrospectively identified $(n=$ 1875). Regardless of the localization of the anastomosis an end-end anastomosis was always performed. In the case of rectal anastomosis double stapling technique using a circular stapler with a diameter of $33 \mathrm{~mm}$ was used and coloanal anastomosis was done with a single layered single-stitch suture with polydioxanone USP 5-0, while in the case of colonic anastomosis a hand-sewn anastomosis was done using a continuous double-layered suture with polydioxanone USP $5-0$.

The policy on when to construct a temporary loop ileostomy ( $n=257$ cases, 13.7\%) was as follows: Mannheimer Peritonitis-Index [18] higher than 29 and/or low rectal anastomosis up to $6 \mathrm{~cm}$ from anal verge.

The diagnosis of liver cirrhosis/severe fibrosis was based on the finding of a typical nodular surface of the liver during surgery and/or on liver biopsy. Histologically staging of fibrosis/cirrhosis was performed using the Ishak scoring system which defines cirrhosis for stages 5 and 6 and advanced fibrosis in stage 4 [19].

The development of anastomotic leakage and the risk factors were retrospectively assessed based on chart review.

A planned contrast enema was done in more than onethird of the patients $(n=691)$ either at the occasion of another study (prospective) or prior to closure of temporary loop ileostomy. In the remaining patients a CT scan with contrast enema was only done in the case of the presence of signs of anastomotic leakage, such as abdominal pain, fever, and elevation of inflammation markers (e.g., CRP elevation after postoperative day 3).

An anastomotic leak was defined as the extravasation of water-soluble contrast in the contrast enema or CT scan, a detected fluid collection (containing air bubbles and/or surrounded by a wall with contrast enhancement), fecal abdominal drainage, the intraoperative finding of anastomotic leakage, or the combination of two or more of these factors. An overview of the study methodology is presented in Figure 1.
TABle 1: Patients' characteristics.

\begin{tabular}{|c|c|c|c|}
\hline Risk factor & $\begin{array}{l}\text { Liver cirrho- } \\
\text { sis/severe } \\
\text { fibrosis (total } \\
n=24 \text { ) }\end{array}$ & $\begin{array}{l}\text { No liver cir- } \\
\text { rhosis/severe } \\
\text { fibrosis (total } \\
n=1851 \text { ) }\end{array}$ & $p$ value \\
\hline Mean age (SD) & $65.5(11.6)$ & $65.0(14.4)$ & 0.943 \\
\hline Male gender & $17(71 \%)$ & $892(48 \%)$ & 0.039 \\
\hline $\begin{array}{l}\text { Median ASA score } \\
\text { (range) }\end{array}$ & $3(2-4)$ & $2(1-5)$ & 0.002 \\
\hline Cardiac comorbidities & $19(79 \%)$ & $818(44 \%)$ & 0.008 \\
\hline Vascular comorbidities & $3(13 \%)$ & $176(10 \%)$ & 0.737 \\
\hline Diabetes & $6(25 \%)$ & $157(8 \%)$ & 0.022 \\
\hline $\begin{array}{l}\text { Pulmonary } \\
\text { comorbidities }\end{array}$ & $9(38 \%)$ & $224(12 \%)$ & 0.003 \\
\hline Tobacco abuse & $7(29 \%)$ & $269(15 \%)$ & 0.094 \\
\hline Obesity & $18(75 \%)$ & $948(51 \%)$ & 0.086 \\
\hline Dementia & $3(13 \%)$ & $20(1 \%)$ & 0.004 \\
\hline $\begin{array}{l}\text { Immunosuppressive } \\
\text { drugs }\end{array}$ & $1(4 \%)$ & $83(4 \%)$ & 1.000 \\
\hline $\begin{array}{l}\text { Nonsteroidal } \\
\text { anti-inflammatory } \\
\text { drugs }\end{array}$ & $4(17 \%)$ & $248(13 \%)$ & 0.770 \\
\hline Presence of cancer & $11(46 \%)$ & $537(29 \%)$ & 0.131 \\
\hline Presence of peritonitis & $4(17 \%)$ & $173(9 \%)$ & 0.294 \\
\hline $\begin{array}{l}\text { Large bowel } \\
\text { obstruction }\end{array}$ & $1(4 \%)$ & $103(6 \%)$ & 1.000 \\
\hline
\end{tabular}

SD: standard deviation; ASA: American Society of Anesthesiologists.

2.1. Statistics. Results are expressed as median and range or mean and standard deviation whenever appropriate. Categorical data was analyzed with the two-sided Fisher's exact test. Continuous data was analyzed with the Wilcoxon rank sum score. Multivariate analyses were done by logistic regression. $p$ values $<0.05$ were considered statistically significant.

2.2. Ethics Statement. This retrospective study was approved by the ethical committee of northwestern and central Switzerland (EKNZ Number BASEC 2016-01311).

\section{Results}

The overall anastomotic leakage rate was 2.7\% (50/1875). Among patients who developed an anastomotic leakage $n=6$ (12\%) were asymptomatic and only detected by imaging, $n=$ 8 (16\%) were managed conservatively, and $n=36(72 \%)$ required revision laparotomy.

The patients' characteristics are shown in Table 1 and the results of the univariate analyses of the risk factors for an anastomotic leak are shown in Table 2. The significantly higher leak rate in the case of presence of liver cirrhosis/severe fibrosis is shown in Figure 2.

Table 3 shows the results of the multivariate analyses where only male gender, lower albumin level, intake of immunosuppressive drugs, and the presence of severe fibrosis/cirrhosis remained statistically significant predictors of the development of an anastomotic leak after colonic surgery. 
TABLE 2: Results of the univariate analyses of the risk factors of anastomotic leakage after colonic anastomosis.

\begin{tabular}{|c|c|c|c|}
\hline Risk factor & $\begin{array}{l}\text { Anastomotic } \\
\text { leak }(n=50)\end{array}$ & $\begin{array}{l}\text { No anastomotic } \\
\text { leak }(n=1805)\end{array}$ & $p$ value \\
\hline Mean age (SD) & $68.8(14.9)$ & $64.9(14.4)$ & 0.028 \\
\hline Male gender & $n=33$ & $n=876$ & 0.021 \\
\hline $\begin{array}{l}\text { Median ASA score } \\
\text { (Range) }\end{array}$ & $2(1-4)$ & $2(1-5)$ & 0.156 \\
\hline $\begin{array}{l}\text { Cardiac } \\
\text { comorbidities }\end{array}$ & $n=28$ & $n=810$ & 0.322 \\
\hline $\begin{array}{l}\text { Vascular } \\
\text { comorbidities }\end{array}$ & $n=5$ & $n=174$ & 1.000 \\
\hline Diabetes & $n=10$ & $n=153$ & 0.022 \\
\hline $\begin{array}{l}\text { Pulmonary } \\
\text { comorbidities }\end{array}$ & $n=9$ & $n=224$ & 0.396 \\
\hline Tobacco abuse & $n=7$ & $n=269$ & 0.437 \\
\hline Obesity & $n=28$ & $n=938$ & 1.000 \\
\hline Dementia & $n=2$ & $n=21$ & 0.142 \\
\hline $\begin{array}{l}\text { Immunosuppressive } \\
\text { drugs }\end{array}$ & $n=7$ & $n=77$ & 0.010 \\
\hline $\begin{array}{l}\text { Nonsteroidal } \\
\text { anti-inflammatory } \\
\text { drugs }\end{array}$ & $n=7$ & $n=245$ & 1.000 \\
\hline Presence of cancer & $n=16$ & $n=532$ & 1.000 \\
\hline $\begin{array}{l}\text { Presence of } \\
\text { peritonitis }\end{array}$ & $n=5$ & $n=172$ & 1.000 \\
\hline $\begin{array}{l}\text { Large bowel } \\
\text { obstruction }\end{array}$ & $n=3$ & $n=101$ & 1.000 \\
\hline $\begin{array}{l}\text { Liver cirrhosis or } \\
\text { severe fibrosis }\end{array}$ & $n=3$ & $n=21$ & 0.024 \\
\hline $\begin{array}{l}\text { Mean (SD) white } \\
\text { blood cell count } \\
(1 / 10 E 9)\end{array}$ & $8.5(3.8)$ & $8.2(4.0)$ & 0.300 \\
\hline $\begin{array}{l}\text { Mean (SD) } \\
\text { haemoglobin level }\end{array}$ & $12.7(2.4)$ & $13.3(2.0)$ & 0.084 \\
\hline $\begin{array}{l}\text { Mean (SD) sodium } \\
\text { level }\end{array}$ & $138.9(4.2)$ & $140.0(3.1)$ & 0.471 \\
\hline $\begin{array}{l}\text { Mean (SD) } \\
\text { potassium level }\end{array}$ & $4.1(0.5)$ & $4.1(1.1)$ & 0.757 \\
\hline $\begin{array}{l}\text { Mean (SD) } \\
\text { creatinine level }\end{array}$ & $88.4(48)$ & $79.6(43.6)$ & 0.131 \\
\hline $\begin{array}{l}\text { Mean (SD) albumin } \\
\text { level }\end{array}$ & $37.6(4.8)$ & $40.2(5.7)$ & $<0.001$ \\
\hline
\end{tabular}

SD: standard deviation; ASA: American Society of Anesthesiologists.

3.1. Subgroup Analyses. Patients with liver cirrhosis/severe fibrosis with anastomotic leakage revealed Child-PughTurcotte scores A $(n=1)$ and B $(n=2)$, while those without anastomotic leakage had the following Child-Pugh-Turcotte scores A $(n=14), \mathrm{B}(n=4)$, and C $(n=1) ; n=2$ missing data. Patients with Child B or C score had no significantly higher anastomotic leakage rate after colorectal surgery than those with Child A score $(p=0.227)$.

From $n=79$ patients with colorectal surgery without performed anastomosis $n=72$ patients had sphincter saving procedures, while $n=7$ had nonsphincter saving procedures.

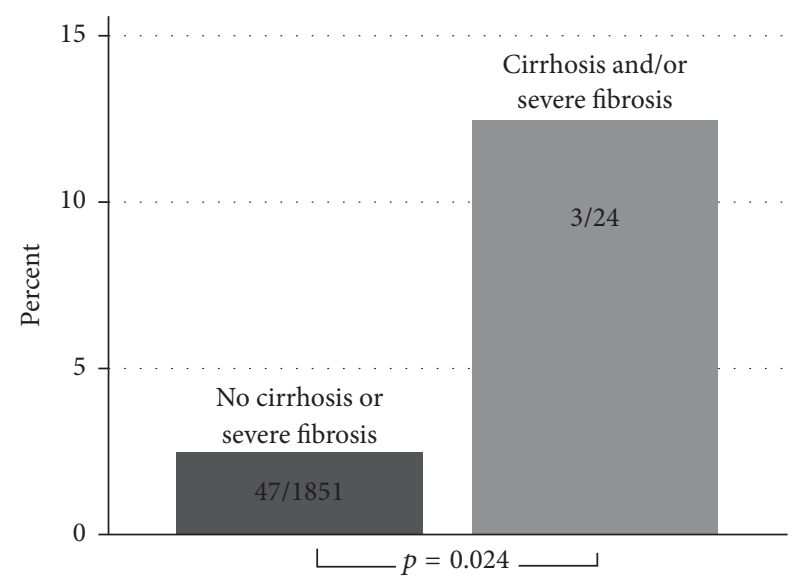

FIGURE 2: Anastomotic leak rate in absence versus in presence of liver cirrhosis and/or severe fibrosis.

TABLE 3: Results of the multivariate analyses of the detected risk factors for anastomotic leakage after colonic anastomosis.

\begin{tabular}{lccc}
\hline Risk factor & Odds ratio & $\begin{array}{c}95 \% \text { confidence } \\
\text { interval }\end{array}$ & $p$ value \\
\hline Male gender & 2.3 & $1.1-4.4$ & 0.021 \\
Age & 1.0 & $1.0-1.1$ & 0.422 \\
Diabetes & 1.4 & $0.6-3.5$ & 0.439 \\
Albumin level & 1.0 & $0.9-1.0$ & 0.042 \\
$\begin{array}{l}\text { Immunosuppressive } \\
\text { drugs }\end{array}$ & 2.9 & $1.0-7.9$ & 0.045 \\
$\begin{array}{l}\text { Liver cirrhosis or } \\
\text { severe fibrosis }\end{array}$ & 4.1 & $1.1-15.5$ & 0.036 \\
\hline ASA:Amerin Socty
\end{tabular}

ASA: American Society of Anesthesiologists.

The indications for surgery were $n=26$ perforated sigmoid diverticulitis, $n=14$ anastomotic leakage, $n=7$ colon ischemia, $n=8$ colonic perforation of other origin, $n=11$ colorectal cancer, $n=8$ noncolorectal cancer, $n=3$ chronic inflammatory bowel disease, $n=1$ rectal prolapse, and $n=1$ perianal abscess. The rate of liver cirrhosis in these patients was not significantly higher $(2.5 \%, 2 / 79)$ than in the population with anastomosis performed $(1.3 \%, 24 / 1875, p=0.288)$.

From 71 patients with reversal of a colostomy only two patients had liver cirrhosis/or high-grade fibrosis. These two patients did not develop anastomotic leakage.

\section{Discussion}

Liver cirrhosis is a known major risk factor for postoperative complications in general and colorectal surgery with a reported morbidity of up to $50 \%$ and mortality up to $25 \%$. The severity of the disease correlates with postoperative morbidity and mortality [16]. Surprisingly little is known about the connection between liver cirrhosis and anastomotic leakage after colorectal surgery [17]. Nevertheless surgeons dislike or even avoid performing colonic or rectal anastomosis in patients with liver cirrhosis. 
The present study aimed to determine if liver cirrhosis/severe fibrosis represents a risk factor for leakage after colorectal surgery or not. Indeed the results support the assumption that cirrhosis/severe fibrosis is a significant risk factor for the development of an anastomotic leak after colorectal surgery.

The presented data complies with earlier reports showing that cirrhotic patients are in an immunocompromised state with a high risk for bacterial translocation and septic conditions $[14,20]$. As in other studies hypalbuminemia as a marker of liver dysfunction was shown to be associated with anastomotic leakage [21-23].

Which measures can be taken to lower the risk of anastomotic leakage in colorectal surgery in patients with liver cirrhosis?

First, pharmacotherapy of patients with liver cirrhosis should be optimized prior to surgery, particularly regarding portal hypertension [24]. For the latter, appropriate treatment with nonselective beta-blockers should be implemented. For those nonresponsive to medical therapy, portal hypertension can be lowered by inserting a transjugular intrahepatic portosystemic shunt [25]. However, this is limited to elective procedures and the impact on postoperative outcome is yet unclear [26].

During operation the sequels of anastomotic leakage can be lowered by construction of a temporary loop ileostomy. But the risk for complications after construction of temporary loop ileostomy (peristomal leaking, infection, peristomal eventration, bleeding from peristomal varices, and complications related to stoma closure) seems to be elevated in patients with liver cirrhosis as well $[6,27]$. Thus the role of a temporary loop ileostomy in colorectal surgery in the presence of liver cirrhosis and/or severe fibrosis remains open.

The diagnosis of liver cirrhosis/severe fibrosis was defined as typical nodular surface of the liver described by the surgeon and/or histological diagnosis of liver cirrhosis/severe fibrosis by liver biopsy. Due to possible sampling error of liver biopsy in liver cirrhosis about one-third of the diagnoses are missed by biopsy only [28]. The intraoperative typical nodular surface is not an unambiguous marker of liver cirrhosis as it can be absent in about $1 \%$ of the patients with histologically confirmed liver cirrhosis [28] and it can be present in patients with severe fibrosis [29]. Doing both laparoscopy/laparotomy and liver biopsy improves the diagnostic yield up to $98 \%$ [30]. Thus, we feel that the definition of liver cirrhosis/severe fibrosis in the present study is justified. Furthermore it fits the real world, as during surgery surgeons sometimes have to deal with an unexpected nodular surface of the liver. However, for future, especially prospective studies, noninvasive methods such as transient elastography or shear-wave elastography potentially allow for improved risk stratification.

4.1. Limitations. The main drawback of this study is its retrospective design. However, we tried to minimize a potential bias by including all consecutive patients registered in a prospective database who had colorectal resection with or without anastomosis at the same institution in a predefined period of ten years. No selection bias due to not performing colonic or rectal anastomosis in patients with liver cirrhosis could be detected.

Although the study has some limitations, we feel that the results of this study are valid and that colorectal surgeons should be aware of the higher risk of anastomotic leakage in patients with liver cirrhosis or high-grade fibrosis.

Clearly, to confirm the results of the present study a prospective study should be performed.

\section{Conclusion}

Patients with liver cirrhosis or severe fibrosis have an increased leak rate after colonic anastomosis.

\section{Competing Interests}

The authors declare that there are no competing interests regarding the publication of this paper.

\section{Authors' Contributions}

Samuel A. Käser and Irina Hofmann contributed equally.

\section{References}

[1] C. F. Gholson, J. M. Provenza, and B. R. Bacon, "Hepatologic considerations in patients with parenchymal liver disease undergoing surgery," American Journal of Gastroenterology, vol. 85, no. 5, pp. 487-496, 1990.

[2] H. E. Rice, G. E. O'Keefe, W. S. Helton, and K. Johansen, "Morbid prognostic features in patients with chronic liver failure undergoing nonhepatic surgery," Archives of Surgery, vol. 132 , no. 8, pp. 880-885, 1997.

[3] G. V. Aranha and H. B. Greenlee, "Intra-abdominal surgery in patients with advanced cirrhosis," Archives of Surgery, vol. 121, no. 3, pp. 275-277, 1986.

[4] C. Sabbagh, D. Fuks, and J.-M. Regimbeau, "Non-hepatic gastrointestinal surgery in patients with cirrhosis," Journal of Visceral Surgery, vol. 151, no. 3, pp. 203-211, 2014.

[5] C. S. Lin, S. Y. Lin, C. C. Chang, H. H. Wang, C. C. Liao, and T. L. Chen, "Postoperative adverse outcomes after non-hepatic surgery in patients with liver cirrhosis," The British Journal of Surgery, vol. 100, no. 13, pp. 1784-1790, 2013.

[6] K. Meunier, S. Mucci, V. Quentin, R. Azoulay, J. P. Arnaud, and A. Hamy, "Colorectal surgery in cirrhotic patients: assessment of operative morbidity and mortality," Diseases of the Colon and Rectum, vol. 51, no. 8, pp. 1225-1231, 2008.

[7] A. M. T. Metcalf, R. R. Dozois, B. G. Wolff, and R. W. Beart Jr., "The surgical risk of colectomy in patients with cirrhosis," Diseases of the Colon and Rectum, vol. 30, no. 7, pp. 529-531, 1987.

[8] W. E. Longo, K. S. Virgo, F. E. Johnson et al., "Risk factors for morbidity and mortality after colectomy for colon cancer," Diseases of the Colon and Rectum, vol. 43, no. 1, pp. 83-91, 2000.

[9] G. C. Nguyen, A. J. Correia, and P. J. Thuluvath, "The impact of cirrhosis and portal hypertension on mortality following colorectal surgery: a nationwide, population-based study," Diseases of the Colon and Rectum, vol. 52, no. 8, pp. 1367-1374, 2009. 
[10] A. A. Ghaferi, A. K. Mathur, C. J. Sonnenday, and J. B. Dimick, "Adverse outcomes in patients with chronic liver disease undergoing colorectal surgery," Annals of Surgery, vol. 252, no. 2, pp. 345-350, 2010.

[11] J. W. A. M. Bosmans, A. C. H. M. Jongen, N. D. Bouvy, and J. P. M. Derikx, "Colorectal anastomotic healing: why the biological processes that lead to anastomotic leakage should be revealed prior to conducting intervention studies," $B M C$ Gastroenterology, vol. 15, article 180, 2015.

[12] M. Bolognesi, M. Di Pascoli, A. Verardo, and A. Gatta, "Splanchnic vasodilation and hyperdynamic circulatory syndrome in cirrhosis," World Journal of Gastroenterology, vol. 20, no. 10, pp. 2555-2563, 2014.

[13] T. Shiota, H. Nakatsukasa, M. Fujiwara et al., "Plasma amino acid imbalance in alcoholic liver cirrhosis," Biochemical medicine, vol. 32, no. 2, pp. 181-188, 1984.

[14] N. Sipeki, P. Antal-Szalmas, P. L. Lakatos, and M. Papp, "Immune dysfunction in cirrhosis," World Journal of Gastroenterology, vol. 20, no. 10, pp. 2564-2577, 2014.

[15] D. A. Telem, T. Schiano, R. Goldstone et al., "Factors that predict outcome of abdominal operations in patients with advanced cirrhosis," Clinical Gastroenterology and Hepatology, vol. 8, no. 5, pp. 451-457, 2010.

[16] M. W. Causey, S. R. Steele, Z. Farris, D. S. Lyle, and A. L. Beitler, "An assessment of different scoring systems in cirrhotic patients undergoing nontransplant surgery," American Journal of Surgery, vol. 203, no. 5, pp. 589-593, 2012.

[17] M. di Bonifácio, R. S. Parra, A. L. N. R. de Almeida, J. J. R. da Rocha, and O. Feres, "Liver cirrhosis on the colonic anastomotic healing in rats," Acta Cirurgica Brasileira, vol. 26, no. 6, pp. 415420, 2011.

[18] M. M. Linder, H. Wacha, U. Feldmann, G. Wesch, R. A. Streifensand, and E. Gundlach, "[The Mannheim peritonitis index. An instrument for the intraoperative prognosis of peritonitis]," Chirurg, vol. 58, no. 2, pp. 84-92, 1987.

[19] K. G. Ishak, H. J. Zimmerman, and M. B. Ray, "Alcoholic liver disease: pathologic, pathogenetic and clinical aspects," Alcoholism: Clinical and Experimental Research, vol. 15, no. 1, pp. 45-66, 1991.

[20] P. Tandon and G. Garcia-Tsao, "Bacterial infections, sepsis, and multiorgan failure in cirrhosis," Seminars in Liver Disease, vol. 28, no. 1, pp. 26-42, 2008.

[21] J. T. Mäkelä, H. Kiviniemi, and S. Laitinen, "Risk factors for anastomotic leakage after left-sided colorectal resection with rectal anastomosis," Diseases of the Colon and Rectum, vol. 46, no. 5, pp. 653-660, 2003.

[22] D. Ionescu, C. Tibrea, and C. Puia, "Pre-operative hypoalbuminemia in colorectal cancer patients undergoing elective surgery-a major risk factor for postoperative outcome," Chirurgia, vol. 108, no. 6, pp. 822-828, 2013.

[23] C.-C. Lai, J.-F. You, C.-Y. Yeh et al., "Low preoperative serum albumin in colon cancer: a risk factor for poor outcome," International Journal of Colorectal Disease, vol. 26, no. 4, pp. 473-481, 2011.

[24] M. Pericleous, A. Sarnowski, A. Moore, R. Fijten, and M. Zaman, "The clinical management of abdominal ascites, spontaneous bacterial peritonitis and hepatorenal syndrome: a review of current guidelines and recommendations," European Journal of Gastroenterology \& Hepatology, vol. 28, no. 3, pp. e10e18, 2016.
[25] D. Azoulay, F. Buabse, I. Damiano et al., "Neoadjuvant transjugular intrahepatic portosystemic shunt: a solution for extrahepatic abdominal operation in cirrhotic patients with severe portal hypertension," Journal of the American College of Surgeons, vol. 193, no. 1, pp. 46-51, 2001.

[26] E. Vinet, P. Perreault, L. Bouchard et al., "Transjugular intrahepatic portosystemic shunt before abdominal surgery in cirrhotic patients: a retrospective, comparative study," Canadian Journal of Gastroenterology, vol. 20, no. 6, pp. 401-404, 2006.

[27] C. Fucini, B. G. Wolff, and R. R. Dozois, "Bleeding from peristomal varices: perspectives on prevention and treatment," Diseases of the Colon \& Rectum, vol. 34, no. 12, pp. 1073-1078, 1991.

[28] J. Poniachik, D. E. Bernstein, K. R. Reddy et al., "The role of laparoscopy in the diagnosis of cirrhosis," Gastrointestinal Endoscopy, vol. 43, no. 2, pp. 568-571, 1996.

[29] A. Colli, M. Fraquelli, M. Andreoletti, B. Marino, E. Zuccoli, and D. Conte, "Severe liver fibrosis or cirrhosis: accuracy of US for detection-analysis of 300 cases," Radiology, vol. 227, no. 1, pp. 89-94, 2003.

[30] R. Orlando, F. Lirussi, and L. Okolicsanyi, "Laparoscopy and liver biopsy: Further evidence that the two procedures improve the diagnosis of liver cirrhosis: a retrospective study of 1,003 consecutive examinations," Journal of Clinical Gastroenterology, vol. 12, no. 1, pp. 47-52, 1990. 


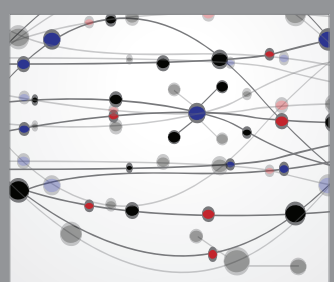

The Scientific World Journal
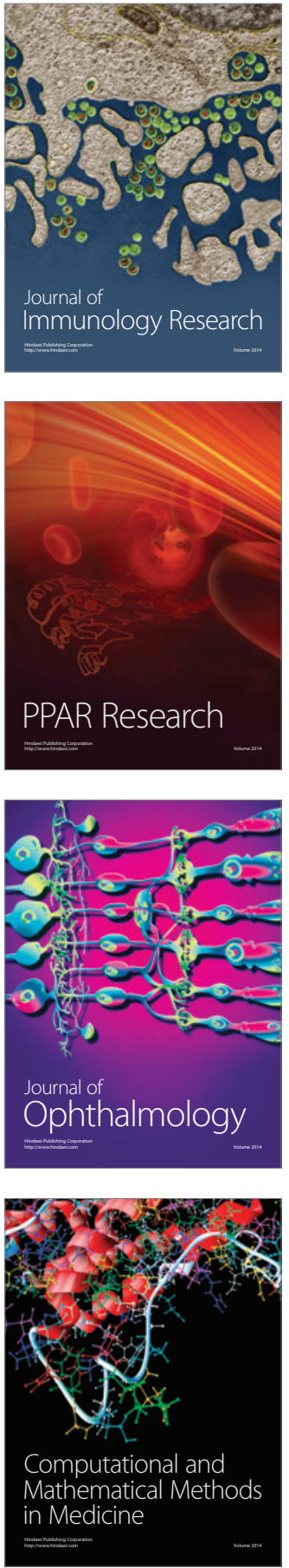

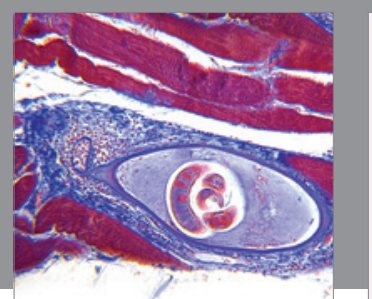

Gastroenterology Research and Practice

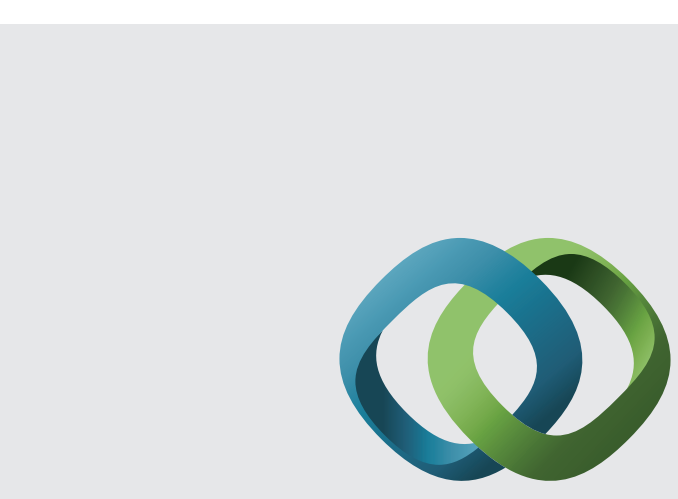

\section{Hindawi}

Submit your manuscripts at

http://www.hindawi.com
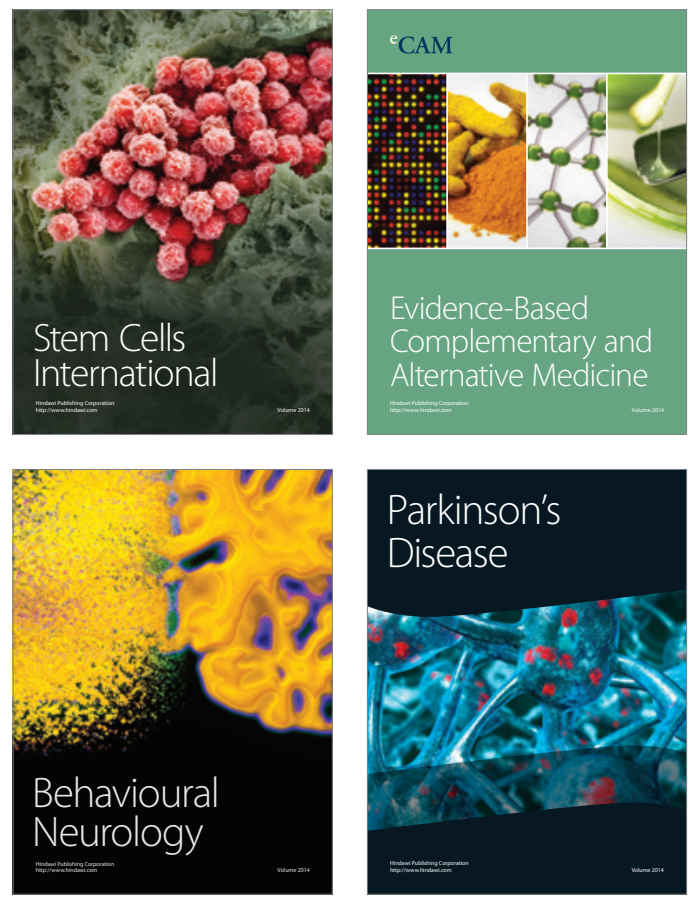
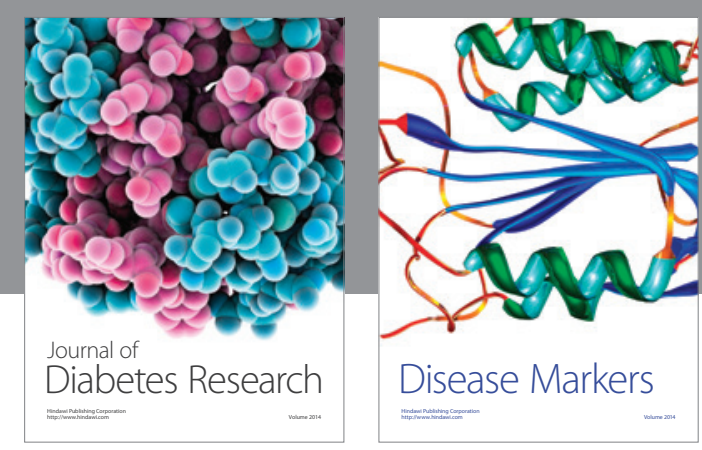

Disease Markers
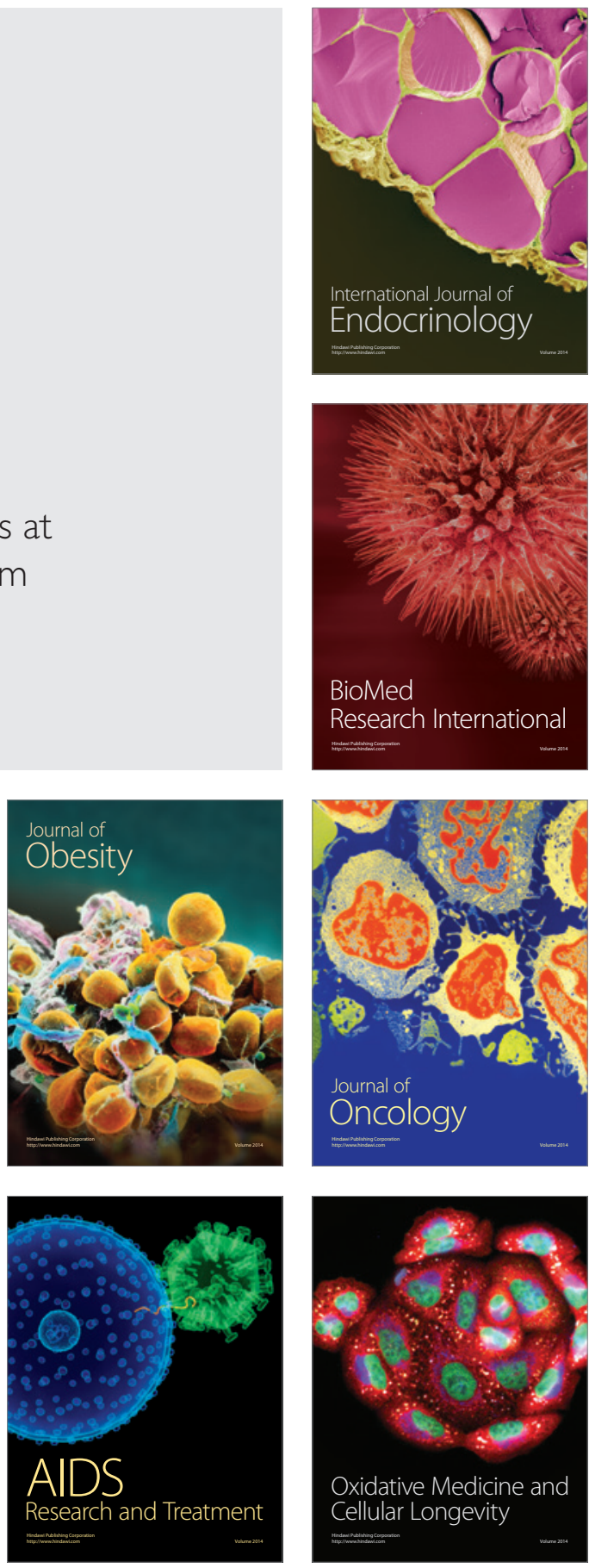